\title{
Incoming CMA president seeks balance for a divided medical profession
}

\author{
— Cite as: CMAJ 2018 September 17;190:E1116-7. doi: 10.1503/cmaj.109-5658
}

Posted on cmajnews.com on Aug. 28, 2018.

t's been a turbulent year for Canadian physicians, but incoming Canadian

Medical Association (CMA) president Dr. Gigi Osler is hoping to chart a course for calmer waters. At a time when physicians have been divided over issues like tax reform and are pushing back against the changing direction of their national association, Osler says she aims to be a "positive, collaborative force that can bring physicians together."

That starts with tackling burnout and poor work-life balance in medicine, she explains. Possible solutions, like rescheduling meetings to avoid childcare conflicts, can be simple, Osler says. But these solutions will require the support of medical leaders who care about physician wellness. "That attitude trickles down and changes the culture."

And culture change is necessary, she says. For years, the profession has focused on individual strategies to address burnout, telling doctors to look after themselves, get enough sleep, eat well and exercise. "All of that is important, but it doesn't address the other issues that drive the burnout, which is the organizational culture," Osler says.

Already, she sees important systematic changes. The CMA board has approved a new vice president and a new division to focus on physician health and wellness. Medical regulators have also moved to include resiliency among the core competencies of the profession, Osler notes.

The 49-year-old Winnipegger embraces the changes that are shaking up the medical profession. She also reflects the growing diversity of Canadian physicians. The daughter of a physician from India and a nurse from the Philippines, Osler, an otolaryngology-head and neck surgeon, is

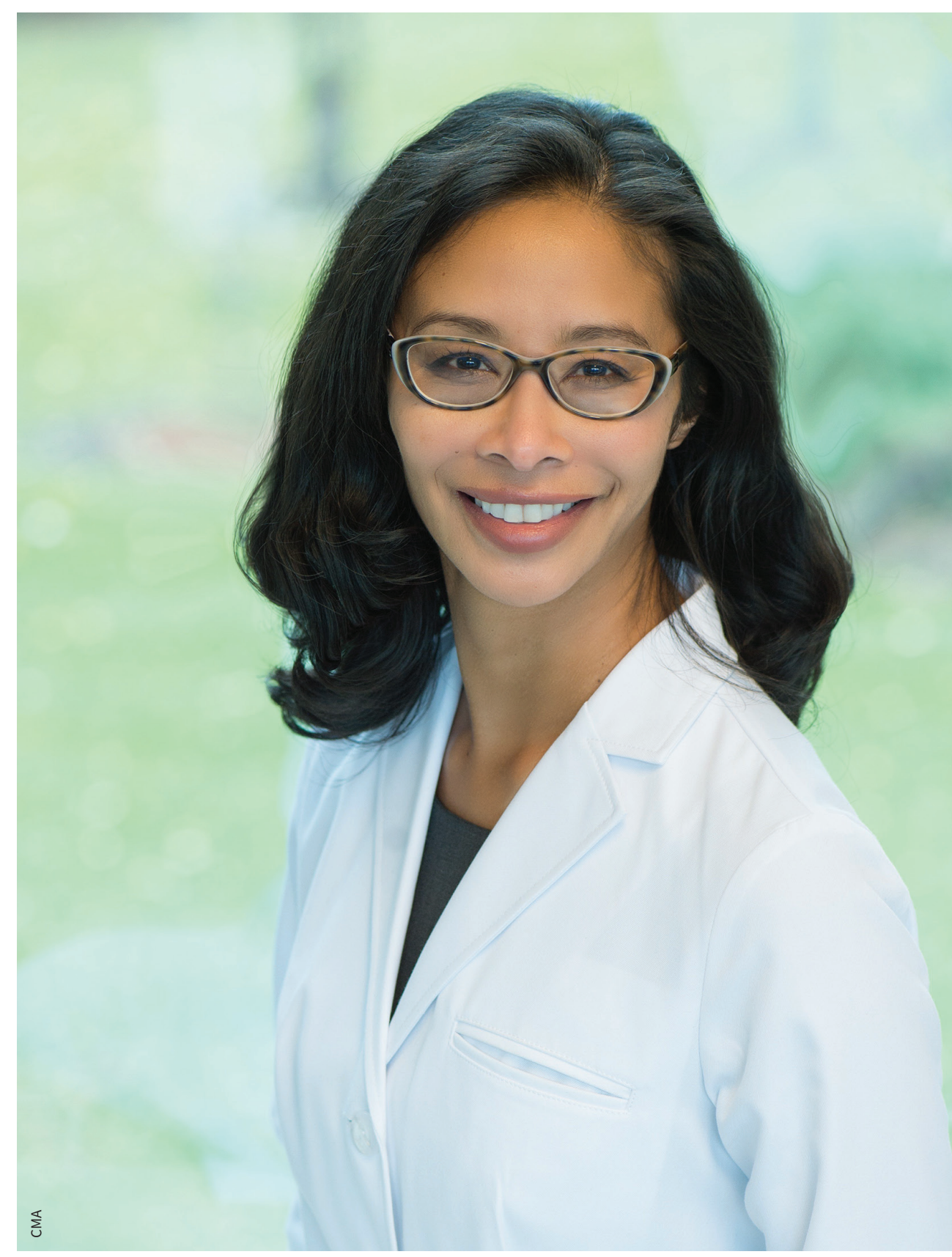

Dr. Gigi Osler will promote physician wellness and diversity as president of the Canadian Medical Association. 
the 151st CMA president. Of the past presidents, 143 have been men and almost all have been white.

Osler says diversity in medical leadership is key for meeting the needs of both doctors and patients. She shares the story of a young black patient who seemed checked out during consultations with his doctors, but became engaged once he had culturally appropriate counselling. She also cites a recent study that showed women were more likely to die from heart attacks when treated by male physicians. "If the women fared worse when treated by male physicians, what about patients of different cultural and ethnic groups? What about people with different gender identity?"

Osler will canvas physicians, medical students and residents for their ideas on promoting diversity and wellness during a tour across this country this fall. "I want to take all that feedback back to the board, back to the association, and say this is what members are telling me," she says. "I want to be a bit of a conduit."

CMA policies and investments must serve the interests of both doctors and patients, Osler says. For example, technological innovation must not leave behind the "regular boots-on-the-ground doctors." In addition to pursuing exciting technologies, Canada's medical leadership must sort out regulatory issues like privacy sharing and whether national licensure is needed to allow physicians to better take advantage of telemedicine, she explains.

Osler also underscores the importance of the CMA as the national voice of physicians. This was driven home when members recently voted against replacing the association's annual General Council meeting with a more nebulous, year-round online dialogue. "Our members are engaged and passionate about having their voices heard and a forum where their voices matter," Osler says. "I heard that loud and clear."

Wendy Glauser, Toronto, Ont. 